\title{
Mitral valve replacement at Tygerberg Hospital: a 5 year follow-up
}

\section{B.J. Barnard", P.J. le Roux" and H.W.J. van Wyk"}

\section{*Division of Cardiothoracic Surgery, Tygerberg Hospital}

"Division of Anaesthesia, Tygerberg Hospital

\author{
Address for correspondence: \\ Dr B.J. Barnard \\ Division of Cardiothoracic Surgery \\ Tygerberg Hospital \\ Parow \\ 7505
}

South Africa

Email:

drbjbarnard@mweb.co.za

Mechanical valve replacement in the mitral position started with introduction of cardiopulmonary bypass in 1960. The St Jude medical bileaflet mechanical prosthesis was introduced in 1977. It has gone through several refinements and is currently the most commonly used mechanical valve prosthesis. ${ }^{(1)}$ Structural failure is no longer a source of significant morbidity with mechanical prosthesis, but thromboembolism and anticoagulant-associated haemorrhage remain significant sources of morbidity and mortality. Progress has been made with the latest generation bioprosthesis, using new fixation and preservation methods. To date long term durability of bioprosthetic valves does not approach that of mechanical prosthesis. ${ }^{(2)}$ This study was conducted to provide midterm follow-up data of isolated mitral valve replacement with mechanical prosthesis. We also wanted to identify preoperative risk factors for mitral valve surgery.

\section{METHODS}

Data were collected both actively (clinic visits and telephonically) and passively (patient files and echocardiographic reports). To determine mortality figures, data collected was further supple-

\section{ABSTRACT}

This study provides 5-year follow-up data of isolated mitral valve replacements with mechanical prosthesis at a large South African tertiary hospital. It also assessed the significance of pre-operative parameters to predict mortality. This is a retrospective study of 187 patients that underwent isolated mitral valve replacement at Tygerberg Hospital from Jan 1998-Dec 2002. Twenty seven patient's data was incomplete and they were excluded from the study. All patients had rheumatic mitral valve disease and the valve lesions included mitral incompetence, mitral stenosis and mixed mitral valve disease. All patients had a mechanical prosthesis implanted (St Jude medical or Orbis bileaflet valves). The mean follow-up time was 5.41-years. The 30 day mortality was $5.62 \%$ and the 5 -year survival was $80 \%$. Pre-operative risk factors that significantly increased mortality were pulmonary hypertension and mitral stenosis. Valve-related complications were more common in this series compared to other First World populations but our results compare well with other Third World population groups. Valve thrombosis $4.32 \%(0.8 \% / y r)$, thromboembolism $8.71 \%$ ( $1.61 \% / y r)$, anticoagulant related haemorrhage $6.87 \%(1.27 \% / y r)$, prosthetic valve endocarditis $3.08 \%$ (0.57\%/yr) and re-operation $8.12 \%$ ( $1.5 \% / y r)$.

Conclusion: Mechanical valve replacement for mitral valve disease that requires valve replacement is still a good treatment option even in third world population groups. In our series, severe pulmonary hypertension, mitral stenosis and reoperation was statistically significantly more common in the "non-survivors" group. SAHeart 20 10; 7:30-37

mented by patient records from the morgue at Tygerberg Hospital and the death register from forensic pathology from the University of Stellenbosch. From Jan 1998-Dec 2002, 187 consecutive, isolated mitral valve replacements were done at Tygerberg Hospital. Twenty seven patients had incomplete data and they were excluded from the study. These patients could not be contacted and they were never seen at any follow-up clinic. The follow-up was 85.56\% complete. The average follow-up time was 5.41 years. The average age of the patients was $34.86+/$-16.1 years. All 
patients had a mechanical prosthesis implanted (St Jude medical or Orbis bileaflet valve) and all patients had rheumatic mitral valve disease. Tricuspid valve repair was done in only 4 patients.

\section{Selection criteria were the following:(3)}

Mitral stenosis: $\quad$ a mean gradient $>12 \mathrm{mmHg}$ or valve area $<1.5 \mathrm{~cm}$ square, in a valve that is not suitable for balloon valvuloplasty.

Mitral incompetence:4+ MI with or without symptoms $3+\mathrm{MI}$ with symptoms or LVED that progress at follow-up

Endocarditis: $\quad 3$ or $4+$ MI with or without symptoms

Uncontrolled sepsis

Organism resistant to treatment

Annular abscess

Intracardial fistula

Vegetation $>$ I cm on valve leaflets

Multiple emboli despite appropriate antibiotics

Forty seven patients presented with predominantly mitral stenosis, 55 had mitral incompetence and 39 presented with mixed mitralvalve disease. Thirteen patients had reoperations during the study period. Standard echocardiographic assessment was performed on all patients and included left ventricular end-diastolic dimension
(LVED), left atrial dimension (LA), ejection fraction (EF) and pulmonary artery pressure (Table I).

\section{OPERATIVE TECHNIQUES}

All operations were performed with cardiopulmonary bypass and had moderate hypothermia (30-32 degrees Celsius).The ascending aorta was cannulated and bicaval venous cannuli was used. Cold crystalloid cardioplegic solution was administered via the aortic root every 20 minutes. Topical pericardial cooling was also done for extra myocardial protection. Mitral valve replacement was performed with single pledgeted sutures in the annules and a left ventricular vent was placed trough the mitral valve before the atrium was closed. Emergency reoperations were done in 3 cases via right thoracotomy with cannulation of the femoral artery and right atrium. Surgery was done under $\mathrm{CO} 2$ field on a beating heart. All the chordae were resected with the stenotic valves and the posterior leaflet and chordae was not resected during replacement of incompetent valves.

\section{Post-operative management}

Subcutaneous Heparin was started as soon as mediastinal drainage stopped. All patients were started on Warfarin day I post operatively and Heparin was stopped when the INR reached 2-4. The average follow-up time was 5.41 years. Patients were asked to return to the clinic at 1.3 and 6 months post-operatively and then every 6 months. Monthly INR readings were done at their local clinics and the Warfarin dose was adjusted accordingly.

TABLE I: Patient profile according to echocardiographic findings. The table indicates the percentages of the total number of patients for each echocardiographic parameter

\begin{tabular}{|c|c|c|c|c|c|}
\hline \multirow[t]{2}{*}{ EF } & $<50 \%$ & $50-60 \%$ & $60-70 \%$ & $70-80 \%$ & \\
\hline & $3.6 \%$ & $20.85 \%$ & $46.62 \%$ & $28.83 \%$ & \\
\hline \multirow[t]{2}{*}{ LVED } & $<45 \mathrm{~mm}$ & $46-55 \mathrm{~mm}$ & $56-65 \mathrm{~mm}$ & $66-75 \mathrm{~mm}$ & $>75 \mathrm{~mm}$ \\
\hline & $16.18 \%$ & $39.88 \%$ & $28.32 \%$ & $13.29 \%$ & $2.31 \%$ \\
\hline \multirow[t]{2}{*}{ LA } & $<45 \mathrm{~mm}$ & $46-55 \mathrm{~mm}$ & $56-65 \mathrm{~mm}$ & $66-75 \mathrm{~mm}$ & $>75 \mathrm{~mm}$ \\
\hline & $17.34 \%$ & $43.35 \%$ & $27.16 \%$ & $8.67 \%$ & $3.46 \%$ \\
\hline \multirow[t]{2}{*}{ Pulmonary pressure } & $<30 \mathrm{mmHg}$ & $30-39 \mathrm{mmHg}$ & $40-49 \mathrm{mmHg}$ & $50-59 \mathrm{mmHg}$ & $>60 \mathrm{mmHg}$ \\
\hline & $24.02 \%$ & $17.54 \%$ & |4.93\% & |4.28\% & $29.22 \%$ \\
\hline
\end{tabular}

EF: ejection fraction, LVED: left ventricular end-diastolic dimension, LA: left atrium. 


\section{DEFINITIONS AND DATA ANALYSIS(4)}

\section{Mortality}

30 day mortality is death within 30 days of surgery irrespective of where the patient might be.

5 year survival is the total amount of patients that was alive at average 5 years post-operatively.

Late mortality is death after 30 days and before 10 years postoperatively

\section{Valve-related mortality}

Valve-related mortality included valve complications that resulted in the late death of the patient.

\section{Non-structural valve dysfunction}

This is incompetence or stenosis which was not caused by intrinsic valve dysfunction as diagnosed by reoperation, autopsy, or clinical investigation (infection and thrombosis excluded).

Example: pannus, paravalvular leak, clinically important intravascular haemolytic anaemia, inappropriate sizing or positioning.

\section{Valve thrombosis}

Any thrombi stuck to or close to the prosthesis which influences the normal functioning of the valve or is sufficiently large to warrant treatment. Valve thrombus found at autopsy in a patient whose cause of death was not valve-related or found at operation for an unrelated indication should also be counted as valve thrombosis. Infection excluded.

\section{Thromboemboli}

Any embolic event that occurs in the absence of infection after the immediate preoperative period. It may be manifested by a neurological event or non cerebral embolic event.

\section{Cerebrovascular incident}

Is a prolonged $(>72 \mathrm{~h})$, or permanent neurological deficit that is usually associated with abnormal results of magnetic resonance imaging or computed topographic scans. Patients with minimal, atypical, or protean symptoms that lead to radiographic imaging demonstrating an acute ischaemic event are considered to have sustained a stroke.

\section{Bleeding}

Any internal or external bleeding that leads to transfusion, hospitalisation, permanent damage or death. Major bleeding unexpectedly associated with minor trauma should be reported as a bleeding event but bleeding associated with major trauma or major operation should not.

\section{Valve endocarditis}

Diagnosis is based on the following criteria: (I) Reoperation with evidence of abscess, paravalvular leak, pus, or vegetation confirmed as secondary to infection by histologic or bacteriologic studies. (2) Autopsy findings of abscess, pus, or vegetation involving a repaired or replaced valve.(3) In the absence of reoperation or autopsy, meeting of the Duke criteria for endocarditis.(4) Positive blood cultures are not required for the diagnosis of operated valve endocarditis. Culture negative endocarditis refers only to negative blood culture results and not just the absence of any proof of infection.

Data was entered into a Excel spreadsheet. Statistical analysis was performed using the NCSS 2004 statistical package. (Number Crucher Statistical Systems, Kaysville Utah).

Data was tested for normality using Kolmogorov-Smirnov Test. Parametric data was analysed using students T-test and KruskalWallis one-way ANOVA on ranks. Post-hoc analysis of differences between groups was performed using Tukey-Kramer Multi-Comparison Test. Non-parametric data was analysed with MannWhitney $U$ or Wilcoxon Rank-Sum Test. Proportions were compared using Chi square (Fishers exact test). Survival was plotted using Kaplan Meier-curves. Logistical regression was performed. This was done to evaluate the pre-operative risk factors. P-value of 0.05 was considered significant.

\section{RESULTS}

The 30 day mortality was $5.62 \%$ (9 patients) as shown in Table 2 . The most common cause for early mortality was low cardiac output in the ICU; others include pneumonia and renal failure. 
TABLE 2: Early mortality, from the day of surgery to 30 days postoperatively

\begin{tabular}{l|c|c|}
\hline Cause of death & $\begin{array}{c}\text { Rate as \% of total } \\
\text { nr of patients }\end{array}$ & \begin{tabular}{c} 
Number of patients \\
\hline Low cardiac output in ICU
\end{tabular} \\
\hline Pneumonia & $4.37 \%$ & 7 \\
\hline Renal failure & $0.62 \%$ & । \\
\hline
\end{tabular}

TABLE 3: Late mortality, from I month post operative to the maximum of 9.58 years

\begin{tabular}{|l|c|c|}
\hline Cause of death & $\begin{array}{c}\text { Rate as \% of total } \\
\text { nr of patients }\end{array}$ & \begin{tabular}{c} 
Number of patients \\
\hline Unknown
\end{tabular} 8.75\% \\
\hline Stroke & $3.75 \%$ & 14 \\
\hline Heart failure & $1.25 \%$ & 6 \\
\hline Heart block & $0.62 \%$ & 2 \\
\hline
\end{tabular}

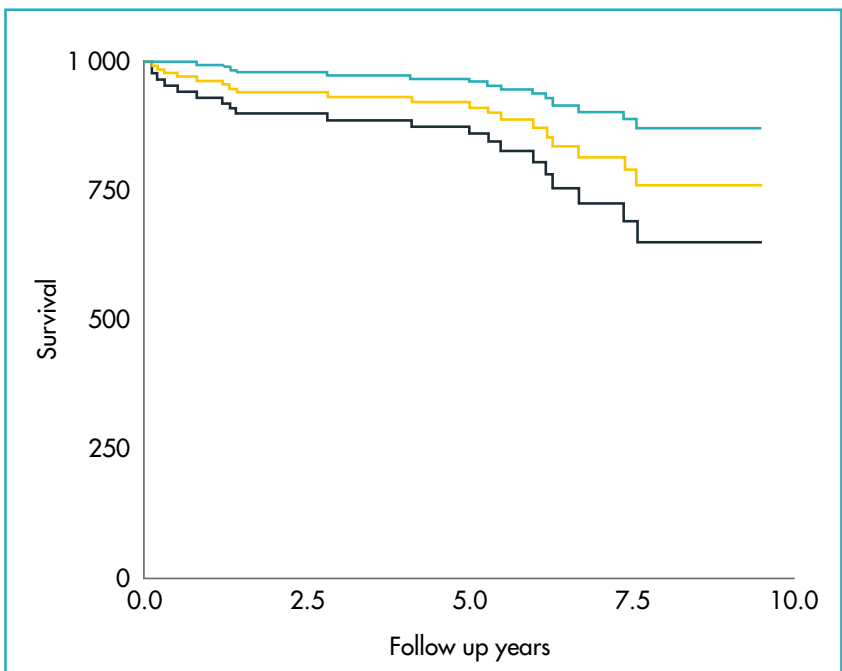

FIGURE I: Showing the Kaplan Meier survival curve with $95 \%$ confidence intervals

\section{TABLE 4: Valve related mortality}

\begin{tabular}{|l|c|c|}
\hline Cause of death & $\begin{array}{c}\text { Rate as \% of total } \\
\text { nr of patients }\end{array}$ & $\begin{array}{c}\text { Number of } \\
\text { patients }\end{array}$ \\
\hline Thromboembolism & $3.75 \%$ & 6 \\
\hline Thrombotic valve obstruction & $2.5 \%$ & 4 \\
\hline Prosthetic valve endocarditis & $1.25 \%$ & 2 \\
\hline Total & $7.5 \% *$ & 12 \\
\hline
\end{tabular}

*If unknown causes of death are presumed to be valve related, total valve related mortality would be $16.25 \%$.
TABLE 5: Reoperation during the study period

\begin{tabular}{|l|c|c|}
\hline Indication & $\begin{array}{c}\text { Rate as \% of total } \\
\mathrm{nr} \text { of patients }\end{array}$ & \begin{tabular}{c} 
Number of patients \\
\hline Clotted valves
\end{tabular} 4.37\% \\
\hline Pannus ingrowth & $1.25 \%$ & 7 \\
\hline Bacterial endocarditis & $1.25 \%$ & 2 \\
\hline Paravalvular leaks & $1.25 \%$ & 2 \\
\hline
\end{tabular}

Late death occurred in 14.37\% (23 patients) as shown in Table 3.

At 5 years the estimated survival was 80\% (Figure I).

Valve-related mortality, shown in Table 4, resulted in 5 year freedom from valve-related mortality of $92.5 \%$. This figure changes to $83.75 \%$ if unknown causes of death are included.

Figure I shows the Kaplan Meier survival curve with 95\% confidence intervals.

Thirteen patients required reoperation during the study period, shown in Table 5. The 30 day mortality for elective reoperation was $0 \%$ and the 30 day mortality for emergency re-operations was $57.14 \%$ and the 5 year freedom from reoperation was $91.87 \%$.

The following pre-operative echocardiographic parameters were evaluated: LVEF, LVED, LA (diameter), PA pressure and valve lesions, (mitral incompetence, mitral stenosis and mixed mitral valve disease) (Table I). In our series, the average pulmonary pressure was statistically, significally higher in the non-survivors compared to survivors. We also found that mitral stenosis was a significant risk factor for 5 year mortality. This is shown in Table 6.

Morbidity

$1.25 \%$ of patients needed a resternotomy for post-operative bleeding and $1.25 \%$ of patients developed sternal sepsis postoperatively. 
TABLE 6: Pre-operative risk factors that were tested are shown in Table 6 . Statistically significant risk factors to predict 5 year mortality are indicated by *

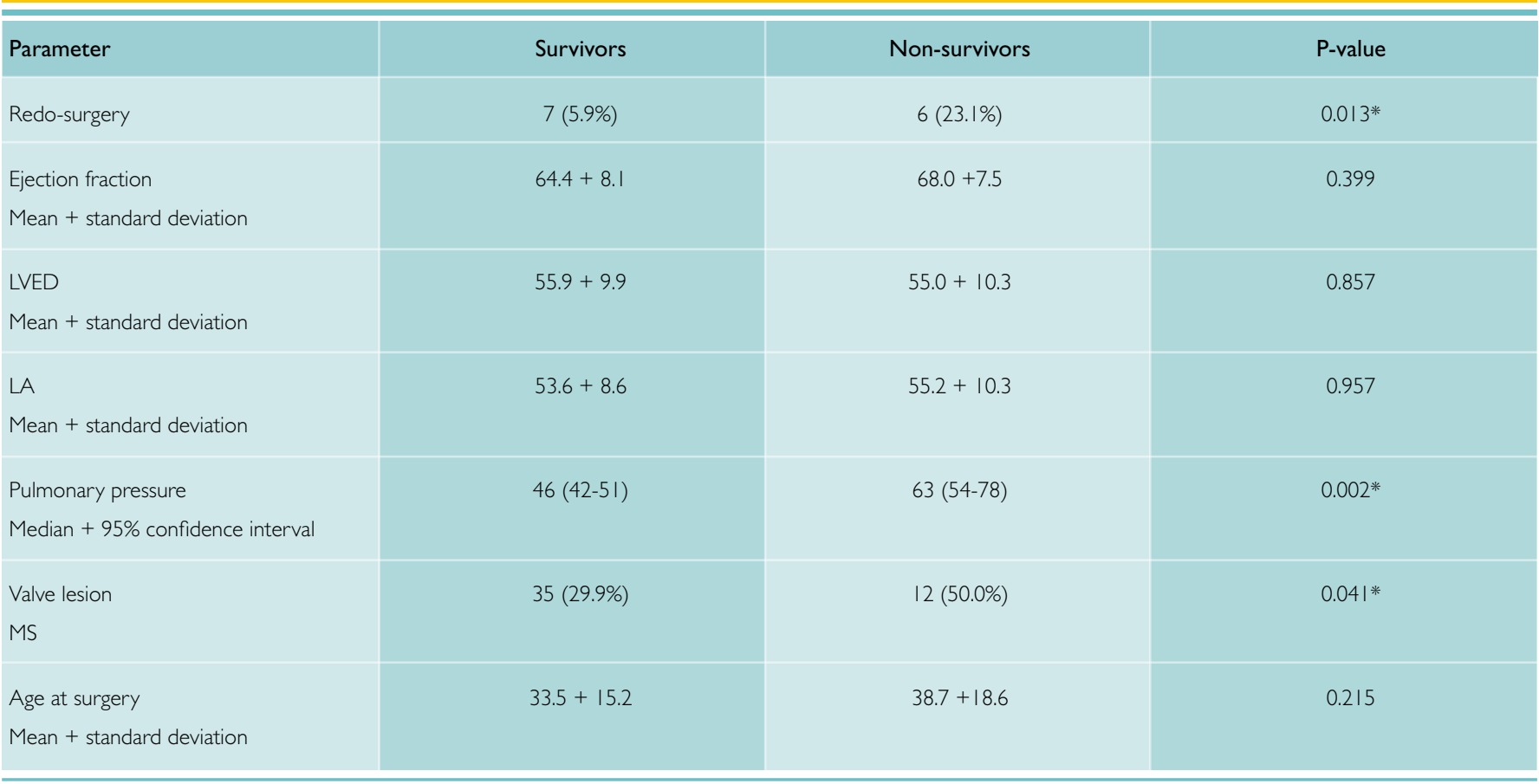

TABLE 7: Major valve related events at Tygerberg Hospital compared to two other University hospitals from first world countries.

\begin{tabular}{|c|c|c|c|}
\hline Valve related events & Tygerberg Hospital & Switzerland Univ Basel ${ }^{(6)}$ & Tokyo Japan ${ }^{(7)}$ \\
\hline Structural valve degeneration & 0 & 0 & $0.24 \% / y r$ \\
\hline Non-structural valve dysfunction: & & $0.1-0.6 \% / y r$ & $0.06 \% / y r$ \\
\hline Pannus & $0.23 \% / y r$ & & \\
\hline Paravalvular leaks & $0.8 \% / y r$ & & \\
\hline Valve thrombosis & $0.8 \% / y r$ & $0.9 \% / y r$ & $0.39 \% / y r$ \\
\hline Emboli & $1.61 \% / y r$ & $0.9 \% / y r$ & $0.39 \% / y r$ \\
\hline Bleeding & $1.27 \% / y r$ & $0.5 \% / y r$ & $0.39 \% / y r$ \\
\hline Bacterial endocarditis & $0.57 \% / y r$ & $0.03-0.1 \% / y r$ & 0 \\
\hline Stroke & $1.61 \% / y r$ & - & - \\
\hline Atrial fibrillation: Pre-op & $32.5 \%$ & - & \\
\hline Post-op & $5.6 \%$ & - & \\
\hline
\end{tabular}


Valve-related events are shown in Table 7. This was compared to similar events in other series ${ }^{(5,6,7)}$ of well controlled First World populations. A third of pre-operative patients were in atrial fibrillation but no atrial ablations were done for atrial fibrillation.

\section{DISCUSSION}

Mechanical valve replacement places huge responsibility on the patient and the medical system of a country. Poor compliance with post-operative therapy, especially anticoagulation, constitutes a significant hazard for patients with mechanical prosthesis. ${ }^{\left({ }^{(8)}\right.}$ For any type of prosthesis, patient compliance with anticoagulation is the most important determinant of thrombosis and thromboembolism. ${ }^{(9,10)}$ The majority of our patients live under poor socioeconomic conditions and consequently, thrombotic and thromboembolic rates were expected to be higher than those in First World countries. Although this proved to be the case, the numbers were lower than anticipated and compared very well with other Third World population groups. (II) The 27 patients lost to followup could be a significant factor in the interpretation of the data. If all those patients are presumed non-survivors during the study period, the 5 year survival would change from $80 \%$ to $68.45 \%$. These patients were lost to follow-up at any clinic and could not be contacted. This included checking patient folders, clinic records, phoning listed telephone numbers and searching the morgue records and death register at our institution.

\section{THROMBOEMBOLISM}

Systemic thromboembolism is a major cause of morbidity in patients with mechanical valves. The thromboembolism incidence for mitral valve replacement with the St Jude medical prosthesis is $2.7 \%$ /pt-year according to M.J. Antunes, ${ }^{(12)}$ in other First World countries like Switserland and Japan, shown in Table 7, the incidence was $0.9 \%$ and $0.39 \%$ respectively. In our series the incidence of thromboembolism was $1.61 \%$ /pt-year (14 patients). Three of these patients (21.42\%) were known to be in atrial fibrillation, although this is surprisingly few, some authors have found no correlation between atrial fibrillation and the increased risk of thromboembolism in patients with mechanical prosthesis. ${ }^{(13,14)}$

\section{THROMBOTICVALVE OBSTRUCTION}

In this series thrombotic obstruction occurred in $4.37 \%$ of patients, this is $0.8 \% / y e a r$ and calculates to $95.63 \%, 5$ year freedom from thrombotic obstruction. This is higher compared to the $0.1 \% /$ pt-year in other studies. ${ }^{(12)}$ The reason for this is poor control of anticoagulation. On admission, six of the patients had an INR value of less than 2 and only one patient had an INR of 2.5 . Thrombolysis should be considered in these patients with some authors reporting good results with double-disc prosthesis. The results after a 42 month period show a 5.8\% mortality, 67\% free from rethrombosis, and $17.6 \%$ embolic complications in some studies. ${ }^{(15)}$ At Tygerberg Hospital a study was done that documented the diagnosis and management of prosthetic valve obstruction. (24) A total of 6 patients received thrombolitic therapy and 4 of these patients were considered too ill for surgery. Four patients (66,6\%), of the thrombolitic group died. The authors proposed that thrombolitic therapy should be considered in patients that are poor surgical candidates. For example patients in cardiogenic shock, NYHA 4, and patients with co-morbidities.

\section{ANTICOAGULANT-RELATED HAEMORRHAGE}

The incidence of anticoagulant-related haemorrhage is a function of intensity of anticoagulation. ${ }^{(13,16)}$ This complication occurred in $6.87 \%$ of patients (1.27\%/year). Of these patients, $45 \%$ had a INR level of less than 2 and in $27 \%$ of cases the INR values were $>10$, another $27 \%$ of patients had no INR values available at the time. Other studies have reported bleeding events of up to $4.3 \%$ / pt-year in Third World population groups. $(13,10,17,18,19,20)$ Antunes showed bleeding events of $0,7 \% / p t$ year, which is low for a Third World population group, but could possibly be related to a lower level of compliance.(II) First World populations like Switzerland ${ }^{(6)}$ and Japan ${ }^{(7)}$ report the incidence of this complication as $0.5 \% /$ year and $0.39 \% /$ year respectively. 


\section{REOPERATION}

A total of 13 reoperations were performed. The 30 day mortality for reoperation was $30.76 \%$. This is higher than in other studies looking at Third World population groups.( ${ }^{(1)}$ Reoperation was found to be a statistically significant risk factor for 5 year mortality. The reason for this is that 7 of the patients were done as emergencies with clotted valves. The 30 day mortality of the emergencies was $57.14 \%$ and the 30 day mortality of the elective reoperations was $0 \%$. Two of the elective patients died during the follow-up period and the 5 year survival of reoperation calculated to $46.15 \%$. We have changed our approach to the emergency surgery (from 200I) and 2 of these patients were done through a right thoracotomy, on a beating heart and femoral bypass, in a carbon dioxide field. These patients both survived.

\section{PROSTHETIC VALVE ENDOCARDITIS}

This complication occurred in $3.12 \%$ of cases (0.57\%/year). This is high compared to other series of First World population groups $(0.03-0.1 \% / \text { year) })^{(5,6,7)}$ and even Third World population studies report an incidence of $0.2 \% /$ pt-year. ${ }^{\left({ }^{\prime I}\right)} \mathrm{A}$ possible explanation for this is the high incidence of pre-operative bacterial endocar$\operatorname{ditis}(16.25 \%)$.

\section{PULMONARY HYPERTENSION}

Pulmonary pressure was statistically significantly higher in the non-survivor group 54 to $78 \mathrm{mmHg}$ (mean $63 \mathrm{mmHg}$ ) versus the survivor group 42 to $51 \mathrm{mmHg}$ (mean $46 \mathrm{mmHg}$ ). This data is supported by the data reported by Cesnjevar(21) who found that with a mean PA pressure of $>50 \mathrm{mmHg}$, post-operative mortality is higher (8.6\% - 13.7\%), depending on the patients age, compared to patients without pulmonary hypertension (3.6\%). One way of predicting post-operative problems with the right ventricle is to measure tricuspid valve annular shortening, echographically. If this is $<11 \%$ it was associated with adverse outcome. ${ }^{(22)}$ Mitral valve replacement should still be offered, albeit with a higher risk, even in the presence of severe pulmonary hypertension as long as pulmonary pressures are below systemic pressure. ${ }^{(23)}$

\section{MITRAL STENOSIS}

The reason why mitral stenosis was a risk factor for 5 year mortality is still unknown. One possible explanation for this can be the loss of all chordae during valve excision.

This study suffers from a number of weaknesses inherent to a retrospective study including incomplete follow-up data (85\% complete). The INR values of all the patients were not included pre-operatively and at follow-up and there was no data available to indicate the incidence of pregnancy and human immune deficiency virus in patients with prosthetic valve replacement.

\section{CONCLUSION}

Thrombotic obstruction and thromboembolism is higher in a Third World population. Significant bleeding episodes, valve endocarditis and non-structural valve degeneration, were also more common in our study, compared to other First World studies. ${ }^{(5,6,7)}$ Even with the higher morbidity, this study showed an acceptable 5 year post-operative survival. Mechanical valve replacement in the mitral position is still a good option in the younger population, even in a developing country. Pre-operative risk factors predicting 5 year mortality in our study were high pulmonary pressure, pure mitral stenosis and reoperation. 


\section{REFERENCES}

I. Emery RW, Palmquist WE, Mettler E, et al. A new cardiac valve prosthesis: In vitro results Trans Am Soc Artif Int organs 1978;24: 550-556

2. Frank W Selke, Pedro J del Nino, Scott J Swanson. Sabiston and Spencer Surgery of the chest. Seventh edition, volume 2, chapter 72, page 1274.

3. Frank W Selke, Pedro J del Nino, Scott J Swanson. Sabiston and Spencer Surgery of the chest. Seventh edition, volume 2, chapter 72, page 1306-1 307.

4. Edmunds L, Henry Jr, Clarke Richard E, et al. Guidelines for reporting morbidity and mortality after cardiac valvular operations. Journal of Thoracic and Cardiovasc surg, 1996; I 12(3):708-1 I.

5. Jamieson WR, Edwards FH, Schwartz M, et al. Risk stratification for cardiac valve replacement. National cardiac surgery database. Database committee of the Society of Thoracic Surgeons. Ann Thorac Surg. 1999;67(4): 943-951,

6. Burnet FH, Baykut D, Grize L, et al. Single-centre outcome analysis of I 16I patients with St Jude medical and ATS open pivot mechanical heart valves. J. Heart valve disease,2007; 16(02): 151-8.

7. Sezai Akira, Shiono M, Hata M, et al. 40 years experience in mitral valve replacement using Starr Edwards, St Jude Medical and ATS valves Annals Thoracic, Cardiovascular Surgery, 2006; I 2(4):249-56.

8. Antunes MJ. Thrombembolism and anticoagulation: Compliant versus noncompliant population groups. Rabago G, ed. Heart valve replacement. Mt. Kisco, New York Futura Publishing Co, Inc 1987:307- 17.

9. Antunes MJ, Santos LP. Performance of gluteraldehyde preserved porcine bioprosthesis as mitral valve substitute in a young population group. Ann Thorac Surg 1984;37:387-92.

10. Moggio RD, Hammond GL Stansel HC Jr, et al. Incidence of emboli with cloth covered Star-Edwards valve without anticoagulation and varying forms of anticoagulation. J Thorac cardiovasc Surg 1978;75:296-9.

II. Manuel J Antunes, Andre Wessels, Romuald G Sadowsski, et al. Medtronic Hall valve replacement in Third World population group. J Thorac Cardiovasc Surg 1988:95:980-93.

12. Kinsley RH, Antunes MJ, Colsen PR, et al. St Jude medical vale replacement: an evaluation of valve performance. J Thorac Cardiovasc Surg 1986;92:349-60.

13. Miller DC, Oyer PE, Stinson EB, et al. Ten to fifteen year reassessment of the performance characteristics of the Starr-Edwards model 6120 mitral valve prosthesis. J Thorac Cardiovasc Surg 1983;85:I-20.

14. Barnhorst DA, Oxman HA, Connolly DC, et al. Long term follow-ups of isolated replacement of the aortic and mitral valve with Starr-Edwards prosthesis. Am J Cardiol 1975;35:228-33.

15. Ramos Al, Ramos RF, Togna DJ. Fibrinolytic therapy for thrombosis in cardiac valvular prosthesis short and long term results. Arq Bras Cardiol 2003 Oct;8I (4): 393-8,387-92.

16. Venugopal P, Kaul L, lyer KS, et al. Fate of thrombectomised Bjork - Shiley valves: Long term cinefluoroscopic, echocardiographic and hemodinamic evaluation. J Thorac Cardiovasc Surg 1986;91:168-73.

17. Miller DC, Oyer PE, Mitchell RC, et al. Performance characteristics of Star Edwards model I 260 aortic valve prosthesis beyond 10 years. J Thorac Cardiovasc Surg 1984;88:193-207.

18. Teply JF, Grunkemeier GL, Sutherland HD, et al. The ultimate prognosis after valve replacement: an assessment at 20 years. Ann Thorac Surg 1981;32:1 I I-9.

19. Karp RB, Cyrus RJ, Blackstone EH, et al. The Bjork-Shiley valve. Intermediate term follow-up. J Thorac Cardiovasc Surg 1981;81:602-14.
20. Macmanus Q, Grunkemeier GR, Lambert LE, et al. Year of operation as risk factor in the late results of valve replacement. J Thorac Cardiovasc Surg 1980;80:834-4.

21. Cesnjevar RA, Feyrer R, Walther F, et al. High risk mitral valve replacement in sever pulmonary hypertension - 30 years experience. European Journal Cardiothoracic Surgery, 1998; 13(04):344-351.

22. 'Pande S, Agarwal SK, Dhir U, et al. Pulmonary arterial hypertension in rheumatic mitral stenosis: does it affect right ventricular function and outcome of metal valve replacement? Interact Cardiovasc Thorac Surg 2009;9(3): 421-5.

23. Mubeen M, Singh AK, Agarwal SK, et al. Mitral valve replacement in severe pulmonary arterial hypertension. Asian Cardiovasc Thorac Ann. 2008; 16( I):37-42.

24. Taljaard JJ, Doubell AF. Prosthetic valve obstruction at Tygerberg Hospital between January 1991 and February 2001. Cardiovascular Journal of South Africa 2003; | 4: 182- 188 . 